\title{
A formação inicial no curso de artes visuais da UFSM: envolvimentos de estagiários e orientadores $\$$
}

Sandra Agostini ${ }^{1}$

\section{Resumo}

Este artigo é um texto proveniente de uma pesquisa que realizei entre os anos 2006 e 2007, referente ao processo de organização e desenvolvimento de Estágios Curriculares em Cursos de Licenciatura da Universidade Federal de Santa Maria (UFSM), procurando contribuir com sugestões, subsídios e parâmetros para que haja melhorias no processo de organização e desenvolvimento de Estágios Curriculares em Cursos de Licenciatura. Neste artigo, em particular, estudamos apenas o Curso de Licenciatura em Artes Visuais da UFSM, buscando caracterizar o processo de organização e desenvolvimento do Estágio Curricular a partir das "visões" dos vinte e três (23) alunos estagiários e do professor orientador de estágios inseridos neste curso. Como fontes de informação, utilizei questionários de perguntas abertas e grupo de discussão, junto aos alunos estagiários e entrevista estruturada junto ao professor orientador de estágios. Constatei que, o Curso apresenta carga horária pouco superior a prevista pela legislação vigente para as atividades de Estágio Curricular. No geral, todos os alunos estagiários tiveram um bom relacionamento com o professor orientador de estágio, foram orientados para conseguirem sua vaga de estágio na escola, foram bem recebidos pelas escolas que possuem tradição em recebê-los, consideraram sua formação inicial como um momento importante de aprendizagem, e elegeram às disciplinas de "Conhecimento de conteúdo específico" como as que mais contribuíram para a realização dos estágios. Porém, relataram que as escolas não os acompanharam no desenvolvimento do estágio, e, sobretudo, não mostraram preocupação em auxiliar os estagiários em formação, o que indica não haver ações interativas entre as Instituições de Ensino Superior (IES) e as Escolas de Educação Básica (EEB) relativamente comprometidas no processo de Formação Inicial de Professores.

Palavras-chave: Curso de Licenciatura, Estágio Curricular, Formação Inicial de Professores.

§§Este artigo faz parte da Dissertação de Mestrado intitulada "A Organização e o Desenvolvimento de Estágios Curriculares em Cursos de Licenciatura da UFSM: Envolvimentos de Estagiários e Orientadores", defendida no dia 10 de junho de 2008, no Programa de Pós-Graduação em Educação - PPGE do Centro de Educação - CE da Universidade Federal de Santa Maria - UFSM, Santa Maria, RS - Brasil.

1 Mestre em Educação pela Universidade Federal de Santa Maria, Professora da Rede Municipal de Ensino no Município de Chapecó/SC. 


\title{
Initial training in the visual arts course of UFSM: the involvement of the trainees and the advisor
}

\begin{abstract}
This article is a text from a survey that was conducted by me between 2006 and 2007, regarding the process of organization and development of Curricular Traineeships in Degree Courses of the Federal University of Santa Maria (UFSM), seeking to contribute with suggestions, allowances and parameters so that improvements can be made in the organization and development of Curricular Traineeships in Degree Courses. In this article, in particular, only the UFSM Bachelor of Visual Arts course is studied, seeking to characterize the process of organization and development of curricular traineeships from the "views" of the twenty-three (23) student trainees and the traineeship teacher advisor included in this course. As sources of information, questionnaires with open questions and discussion groups were used, together with trainee students, and a structured interview together with the traineeship teacher advisor. I noticed that the Course presents a workload of only a little more than as is dictated by the current legislation for the activities of the Traineeship Stage. Overall, all the student trainees had a good relationship with the traineeship teacher advisor, and were advised how to get their job placement in the school, were well received by the schools which have a tradition of welcoming them, considering their initial training as an important learning moment, and elected the disciplines of "Knowledge of specific content" as those which contributed most to the achievement in the traineeships. However, it reported that the schools have not accompanied them in the development stage and, in particular, showed no concern in assisting the trainees in their formation, which indicates that there are no interactive actions between Higher Education Institutions (HEIs) and the Schools of Basic Education $(\mathrm{SBE})$ and are relatively compromised in the process of initial teacher formation.
\end{abstract}

Keywords: Degree Course, Curriculum Traineeship, Initial Teacher formation.

\section{Considerações Iniciais}

Este trabalho faz parte de uma investigação maior acerca do Estágio Curricular, o qual procurou descrever e questionar a organização e o desenvolvimento dos Estágios Curriculares em cursos de licenciaturas da UFSM (AGOSTINI, 2008), e teve como objetivo buscar sugestões e contribuir para a elaboração de subsídios e parâmetros para as formas de organização e desenvolvimento de Estágios Curriculares em Cursos de Licenciatura. 
Para este estudo, particularmente, estarei enfocando apenas o processo formativo no curso de Licenciatura em Artes Visuais da Universidade Federal de Santa Maria (UFSM). Utilizei, para isso, Projeto Político-Pedagógico (PPP) desse curso, buscando evidenciar como ocorreram as alterações em suas configurações curriculares, e, além disso, para compreender o processo de organização e desenvolvimento de seus Estágios Curriculares, busquei também, informações a partir de questionários de perguntas abertas e grupo de discussão junto aos alunos estagiários, e entrevista estruturada junto ao professor orientador de estágios.

Sabemos que a Formação Inicial de Professores está vinculada, principalmente, ao Estágio Curricular que, geralmente, tem-se resumido a desenvolver atividades de observação, participação e regência. O Estágio Curricular tem a função principal de colocar o futuro professor em contato com o seu campo de trabalho, levando-o a avaliar a sua pertinência e a adequação de sua escolha profissional, bem como os desafios que a prática apresenta e a sua própria satisfação com essa escolha.

Nesse sentido, "o estágio representa para o aluno uma oportunidade de verificar o acerto de sua escolha profissional, já que é o momento em que a situação ensino-aprendizagem se realiza em toda a sua plenitude" (PONTUSCHKA, 1991, p.136). Por isso, o estágio proporciona ao aluno estagiário uma experiência única, durante sua Formação Inicial, sobre como exercer sua profissão a partir da vivência de situações reais de ensino.

O Estágio como componente curricular, nos Cursos de formação de professores tradicionalmente tem sido considerado em muitos casos como uma atividade "prática" de menor importância, no conjunto das disciplinas ditas "teóricas". Sendo essa desarticulação, a grande responsável pelos constantes problemas da dicotomia entre teoria e prática. De acordo com Lima (2004, p.125):

É necessário, portanto, que o Estágio seja pensado por todos os professores e alunos e compreendido como uma atividade teóricoprático, em constante processo de ação/reflexão e fonte inspiradora da seleção dos conteúdos das disciplinas de formação do professor.

A formação inicial de professores desde o final da década de 70 até os dias atuais, tem sido palco de discussões nos meios acadêmicos, devido às modificações decorrentes das leis e normativas legais que tratam da Formação de Professores para a Educação Básica. Entre elas, merece destaque a promulgação da Lei de Diretrizes e Bases - LDB, Lei no 9.394 de 20 de dezembro de 1996, que estabelece as diretrizes e bases da educação nacional, bem como as Resoluções do Conselho Nacional de Educação - CNE/CP no 1 e n० 2 de fevereiro de 2002. 
Na LDBEN - Lei 9.394/96, as discussões ganharam repercussão no que se refere ao Título IV "Dos Profissionais da Educação", especialmente, no Art. 61, Inciso I, Art. 63, Inciso I, Parecer CNE no 04/97 e Art. 65, que permitem aos profissionais egressos de diferentes áreas após uma complementação pedagógica de 540 horas tornarem-se professores.

No âmbito das reformulações curriculares dos Cursos de Formação de Professores estabelecida pela Resolução CNE/CP 1 de 18 de fevereiro de 2002, com base nos Pareceres $9 / 2001^{2} 27 / 2001^{3}$, são estabelecidas as Diretrizes Curriculares Nacionais para a Formação de Professores da Educação Básica, em nível superior, Cursos de Licenciatura, de graduação plena. Também, é pauta de discussões, ao que concerne o Art. 70, no Inciso IV que: "as instituições de formação trabalharão em interação sistemática com as escolas de educação básica, desenvolvendo projetos de formação compartilhados".

E ainda, referente à mesma resolução, o Art. 13, parágrafo 3 define: "O estágio obrigatório a ser realizado em escola de educação básica, e respeitado o regime de colaboração entre os sistemas de ensino, deve ter início desde o primeiro ano a ser avaliado conjuntamente pela escola formadora e a escola campo de estágio".

Outro tema em constante discussão refere-se à aprovação do Conselho Nacional de Educação - CNE/CP 2 de 19 de fevereiro de 2002, que estabelece a duração e a carga horária dos Cursos de Licenciatura Plena, de formação de professores da Educação Básica em nível superior, cursos de Licenciatura, de graduação plena, estipulando no seu inciso II, o aumento da carga horária destinada ao Estágio Curricular Supervisionado para 400 (quatrocentas) horas, tendo início a partir da segunda metade do curso, proporcionando ao estagiário maior tempo de permanência na escola.

Nesta resolução, no parágrafo único, verifica-se também que os alunos que já estão exercendo atividades docentes poderão reduzir pela metade a carga horária exigida para o Estágio Curricular Supervisionado.

Como se pode perceber, frente às novas exigências legais, faz-se necessário uma interação entre a Instituição de Ensino Superior - IES e a Escola de Educação Básica EEB, visando proporcionar uma formação de "melhor qualidade" aos estagiários, futuros

2Estabelece Diretrizes Curriculares Nacionais para a Formação de Professores da Educação Básica, em nível superior, curso de Licenciatura, graduação plena.

3 Dá nova redação ao item 3.6, alínea c, do Parecer CNE/CP 9/2001, que dispõe sobre as Diretrizes Curriculares Nacionais para a Formação de Professores da Educação Básica, em nível superior, curso de Licenciatura, de graduação plena. 
profissionais do ensino. Porém, sabemos que a quantidade do número de horas destinadas ao Estágio Curricular não irá fazer nenhum diferencial na "qualidade" do profissional que se estará formando, se não houver comprometimento e responsabilidade pelas agências formadoras envolvidas neste processo formativo.

\section{Desenvolvimento do Trabalho}

Para compreender os procedimentos utilizados na organização e desenvolvimento de Estágios Curriculares no Curso de Artes Visuais da UFSM, defini para esse estudo como fonte de informações os sujeitos alunos estagiários e professor orientador de Estágios Curriculares e, ainda, utilizei como fontes documentais a legislação referente à Formação de Professores, em específico, as resoluções e os pareceres, e o Projeto-PolíticoPedagógico (PPP) do referido Curso, sendo que este último serviu de fonte para coleta das informações que foram submetidas à análise. E, como instrumentos para coletar as informações junto aos sujeitos utilizei os questionários de perguntas abertas e realizei o grupo de discussão com os alunos estagiários. E, ainda, realizei a entrevista estruturada individual com o professor orientador de estágios.

A preferência pelo questionário de perguntas abertas definiu-se porque esse tipo de questão permite ao entrevistado responder ao questionário com mais liberdade, objetivando assim, conseguir maiores informações para a pesquisa. Como defende Pádua (1996, p.67): "As questões abertas por exigirem uma resposta pessoal, espontânea do informante, trazem dados importantes para uma análise qualitativa, pois as alternativas de respostas não são todas previstas, como no caso das perguntas fechadas".

A opção pelo Grupo de Discussão foi baseada na técnica do Grupo Focal, Matos e Vieira (2002) por ser uma técnica de entrevista possibilita aprofundar as informações sobre o tema mediante às diversas opiniões relatadas pelos depoentes.

A escolha pela entrevista estruturada, ocorreu com o objetivo de aprofundar as discussões sobre o Estágio Curricular e, sobretudo, buscar informações complementares que os estagiários talvez não houvessem mencionado. De acordo com a compreensão de Marconi e Lakatos (2003, p.195): "Entrevista é um encontro entre duas pessoas, a fim de que uma delas obtenha informações a respeito de determinado assunto, mediante uma conversação de natureza profissional".

Nesta pesquisa, também, utilizou-se a integração entre análise qualitativa e quantitativa, pois ambas podem se complementar e assim possibilitar várias interpretações durante a análise dos dados. Segundo Goldenberg (2003, p.62): "a integração da pesquisa 
quantitativa e qualitativa permite que o pesquisador faça um cruzamento de suas conclusões de modo a ter mais confiança que seus dados não são produto de um procedimento específico ou de uma situação particular".

Para desenvolver esse estudo primeiramente, elaborei e utilizei os questionários de perguntas abertas os quais foram entregues a todos os alunos estagiários do referido curso, em duas modalidades: questionário inicial e questionário final e em dois momentos: fase inicial e fase final de Estágio Curricular.

No $1^{\circ}$ semestre de 2006, foram entregues cinco (05) questionários para estagiários em fase inicial de Estágio Curricular e recolhidos quatro (04) questionários. Também, foram entregues cinco (05) questionários aos alunos estagiários em fase final de estágio e recolhidos quatro (04) questionários.

No $2^{\circ}$ semestre de 2006, foram entregues doze (12) questionários para estagiários em fase inicial de estágio e recolhidos apenas seis (06) questionários.

No 10 semestre de 2007 foram entregues vinte e dois (22) questionários aos alunos estagiários em fase inicial de estágio e recolhidos apenas um (01) questionário.

Devido ao baixo retorno do questionário inicial, ainda, durante o $1^{\circ}$ semestre de 2007, resolvi organizar e realizar o Grupo de Discussão. Num primeiro momento, elaborei um roteiro constituído por dez (10) questões, contemplando entre elas parte do questionário inicial e partes do questionário final. Também, elaborei um Termo de Concordância para que fossem autorizadas a gravação e a filmagem da sessão e para a utilização das informações no desenvolvimento desta pesquisa.

Desse modo, realizei o Grupo de Discussão que contou com a participação de treze (13) alunos estagiários.

Para a análise das informações obtidas nos instrumentos utilizados, foram nos estudos realizados por Bardin (1977) que encontrei notável relevância sobre o uso da análise de conteúdo, seguindo algumas orientações para nortear essa análise. Entendo que a análise de conteúdo é mais que uma leitura ipisis litteris de qualquer enunciado, ela se caracteriza por uma análise do trabalho, visando à compreensão crítica do significado das comunicações.

Para organizar as informações obtidas nos questionários, primeiramente, digitei o código 
dos sujeitos questionados $1 \mathrm{~S}-06-\mathrm{AV}-\mathrm{A} 01^{4}$; em seguida, as respostas foram digitadas na íntegra, logo após fiz a leitura das respostas, tantas vezes quanto necessário, para extrair a(s) idéia(s) central(is) expressas na resposta. Após a localização da(s) idéias central(is) nas respostas, agrupei aquelas que faziam referência a uma mesma indicação. Por fim, fiz as constatações apresentando a quantidade de frequências na resposta obtida, e realizei a análise das informações obtidas.

Para a organização das informações obtidas no Grupo de Discussão inicialmente, transcrevi a entrevista ipisis litteris e enviei por correio eletrônico aos participantes das sessões. Após, obter a autorização dos depoentes para a utilização das informações obtidas, as entrevistas foram lidas e relidas tantas vezes quanto necessária para identificar a(s) idéia(s) central(is). Após a localização da(s) idéia(s) central(is) nas respostas, tabulei de acordo com as categorias definidas a priori,e realizei a análise das informações obtidas. Vale lembrar que, para a organização das informações obtidas na entrevista estruturada, os procedimentos utilizados foram os mesmos do Grupo de Discussão.

Conforme o exposto foram essas técnicas utilizadas na coleta e na análise das informações obtidas, pois elas pareceram mais adequadas ao tipo de estudo que realizei.

\section{- Estágio Curricular no Curso de Artes Visuais da UfSM: ações/atividades/formas utilizadas pelo professor orientador}

Após a coleta dos dados junto aos documentos do curso investigado Projeto-PolíticoPedagógico (PPP) e também das narrativas do professor orientador de estágio sistematizei as informações obtidas, que serão apresentadas a seguir.

No Curso de Artes Visuais Licenciatura Plena em Desenho e Plástica do currículo vigente, o Estágio Curricular está organizado em quatro disciplinas sequências ( $5^{\circ}$ a $8^{\circ}$ semestres), sendo todas elas dedicadas a atividades de regência em sala de aula. Os objetivos propostos a serem desenvolvidos nas disciplinas de Estágio Curricular são:

- Aprender a ser professor no campo de situação profissional referente às diferentes realidades;

- Materializar roteiros de aula compartilhados com o professor regente, executando o Projeto de Estágio;

- Reconhecer os diferentes setores da escola e seu funcionamento;

- Construir a competência da docência na ação educativa do Estágio

4 O Código 1S se refere ao Semestre letivo, ou seja, neste exemplo primeiro semestre, 06 ano da coleta, 2006, AV ao Curso, ou seja, Artes Visuais e A01 ao aluno número 1 da amostra. 
Supervisionado;

- Estabelecer relações entre teoria e prática, como pesquisador e profissional atuante;

- Compreender a ação educativa como espaço de pesquisa e extensão;

- Realizar uma exposição didática na escola dos trabalhos produzidos pelos alunos;

- Apresentar e defender o Relatório final do Estágio Supervisionado com banca examinadora.

A partir da breve caracterização do Curso de Artes Visuais da UFSM, constatei que, o Curso apresenta carga horária pouco superior a prevista pela legislação vigente para as atividades de Estágio Curricular, estando nesse ponto em acordo com a Resolução CNE/CP 2/2002.

Quanto ao início das atividades de Estágio Curricular, percebi que o Curso também está em acordo com a Resolução CNE/CP 2/2002.

$\mathrm{Na}$ fala do professor orientador de estágio encontrei o seguinte relato em relação aos encaminhamentos para o Estágio Curricular.

Primeiramente, o professor orientador de estágio entra em contato com as escolas para verificar o número de vagas e turno disponibilizados pela escola. No início das aulas é apresentado aos alunos as escolas e o número de vagas; os alunos são livres para escolher dentre essas escolas e/ou outras de acordo com seus interesses. Posteriormente, os alunos estagiários elaboram um projeto piloto de uma disciplina de observação de aula, na qual os alunos passam a acompanhar as aulas de um colega na escola que eles pretendem estagiar.

Além disso, os alunos fazem um relato de todas as aulas assistidas a partir de um roteiro pré-estabelecido com os itens a serem observados. No entanto, quando o aluno vai para a escola observar ele já tem o projeto numa outra disciplina que antecede a esta.

No semestre seguinte, passa para o Estágio I, no qual ele participa das aulas teóricas e práticas. Na parte teórica, o aluno lê textos participa das dinâmicas; na parte prática ele somente ouve os relatos dos colegas que já estão inseridos nas escolas. Nos Estágios II, III e IV, eles fazem relatos também e é indicada uma lista de Bibliografias que irão auxiliá-los no decorrer do estágio.

A respeito do processo de aceitação e recepção dos alunos estagiários pelas escolas, 
quem os recebeu e de que forma, nas informações obtidas pude destacar que: 0 professor orientador a partir de suas visitas as escolas constatou que a receptividade é maior naquelas escolas que vem recebendo os estagiários desde 2002. Em função de que nessas escolas os professores regentes já tem um conhecimento maior com o trabalho que os estagiários realizaram. Então, eles são bem recebidos. Porém, nas escolas que já houve problemas com os alunos estagiários, não existe essa relação tão amigável. No geral, os seus estagiários foram recebidos pela Diretora ou pela professora regente de turma.

\section{Estágio curricular: a trajetória vivenciada pelos alunos do curso de artes visuais da UFSM}

Após a leitura e sistematização das informações obtidas nos questionários e no grupo de discussão junto aos alunos estagiários, apresentarei uma análise das informações coletadas. No entanto, vale lembrar que as análises se referem ao $1^{\circ}$ e $2^{\circ}$ semestres do ano de 2006 e $1^{0}$ semestre do ano de 2007, sendo que, neste último semestre foram realizados os Grupos de Discussão visando suprir as possíveis falta de informações não obtidas nos questionários.

Em relação à análise, referente às informações obtidas junto aos alunos estagiários sobre as disciplinas que mais contribuíram para a realização do Estágio Curricular constatei que: para o total de nove (09) depoentes, as disciplinas que mais contribuíram para a realização do Estágio Curricular para seis (06) deles foram as disciplinas de "Conhecimento de conteúdo específico". Para um (01) somente as disciplinas de "Conhecimento de conteúdo específico". E para dois (02) todas as disciplinas cursadas contribuíram nesse processo de formação inicial.

A respeito do depoimento de um aluno estagiário, considerando a disciplina de "Conhecimento de conteúdo específico", ou seja, a disciplina "Metodologia de Pesquisa" como a mais importante, houve uma discordância entre os estagiários a respeito dessa colocação, os quais afirmaram que não escolheriam nenhuma disciplina como sendo a mais importante para a realização de Estágio Curricular.

A partir da análise referente à maneira como ocorreu à orientação para os alunos estagiários conseguirem sua vaga na escola para a realização de Estágio Curricular verifiquei que: todos os alunos estagiários foram orientados pelo professor orientador, que entrou em contato com as escolas e solicitou aos estagiários que confirmassem a escolha levando uma carta de apresentação para a professora regente da escola. 
Em alguns casos esse primeiro contato com as escolas é feito diretamente pelo aluno estagiário que procura a escola de acordo com os seus interesses e suas necessidades pessoais para a realização de Estágio Curricular.

Conforme a análise referente a forma como os alunos estagiários foram recebidos e como se relacionaram com as escolas para a realização de Estágio Curricular evidenciei que: dos nove (09) depoentes, sete (07) alegaram que foram bem recebidos pelas escolas e 0 relacionamento foi bom. Com exceção de um (01) deles que foi recebido com indiferença, e também, para um (01) deles a relação com a escola foi quase harmoniosa. Constatei que a maioria (13) dos depoentes quando questionados sobre a forma como foram recebidos pelas escolas, relataram que foram bem recebidos, que as escolas recebem de "braços abertos", porém no decorrer das narrativas percebi que por trás de tal atitude as escolas encobrem uma segunda intenção. O depoimento abaixo é um exemplo disto:

(...) É que nas escolas os professores tem os estagiários pra tapa furo, (sic) pra eles descansa; então no geral, todos eles adoram porque é relax assim dos colegas e na grande maioria das vezes é assim né, eles estão ali bem-vindos. Que bom o estagiário! (GDAV-01)

A partir dos relatos, verifiquei que, os professores regentes não mostraram preocupação em auxiliar o estagiário em formação, mas sim o vem como um substituto para as suas aulas, um "alguém" que vai amenizar sua sobrecarga de trabalho.

Em relação à analise referente à maneira como os alunos estagiários foram acompanhados pelas escolas para a realização do Estágio Curricular constatei que: quatro (04) depoente declararam que não foram acompanhados pelas escolas no decorrer da realização do Estágio Curricular. Com exceção de um (01) depoente que a escola acompanhou por meio de conversas informais. Porém, dois (02) omitiram sua opinião e dois (02) não entenderam a questão proposta.

Percebi que há uma falta de conscientização por parte dos professores regentes de turma em considerar o estagiário um professor apto à profissão, pois ele está em processo de formação, construindo sua identidade docente necessitando de acompanhamento e de todo o auxílio necessário da escola e, sobretudo, do professor regente nesse momento essencial para a sua formação inicial. Segundo Oliveira (2005, p.70):

Se enquanto curso de formação de professores, queremos realmente formar docentes com condições de se inserir nas escolas de modo a propor um ensino significativo, de mudanças nas 
concepções de cultura e valores para a vida, o estágio deverá ser um trabalho coletivo, não só centrado na sala de aula universitária, nem só de mão única dos nossos alunos estagiários, mas de toda equipe de professores da escola.

Conforme a literatura estudada, o Estágio Curricular é considerado a base para exercer a futura profissão. Este depoimento, no entanto, me conduz aos seguintes questionamentos: Que tipo de formação o estagiário recebe? Por que a escola não assume a sua co-responsabilidade no processo de formação inicial?

A respeito do relacionamento dos alunos estagiários com o professor orientador, durante o desenvolvimento dos Estágios Curriculares foi considerado como aspecto positivo o acompanhamento do professor orientador no estágio de forma satisfatória.

Em relação às colocações feitas pelos estagiários, a respeito da participação do professor regente na elaboração de seus planejamentos, verifiquei que o professor regente não participou dessas atividades.

A partir das colocações feitas pelos alunos estagiários, a respeito da participação dos professores regentes na condução das aulas, constatei que a maioria deles concedeu apoio, auxílio na manutenção da disciplina e orientações a respeito da turma.

Quanto às narrativas feitas pelos estagiários, a respeito da participação dos professores regentes na avaliação do Estágio Curricular, averiguei que estes não participaram do processo de avaliação do estagiário.

No que se refere aos comentários feitos pelos alunos estagiários a respeito da avaliação do Estágio Curricular, percebi que o Estágio Curricular foi considerado como um momento importante para a formação do futuro professor, um período de aprendizagens que proporciona o contato com as dificuldades da prática pedagógica e permite vivenciar a realidade escolar.

Os resultados mostram, pois, um dado preocupante quanta à falta de acompanhamento da escola aos alunos estagiários durante a realização do Estágio Curricular. Acredito que será desta supervisão/acompanhamento que dependerá o "sucesso" da formação inicial dos futuros professores, além disso, percebi que não há um padrão de acompanhamento das escolas, bem como dos professores regentes de turma. De acordo com Pacheco e Flores (1995, p.47), "Neste meio caminho profissional, o estagiário vive de forma direta ou indireta, sob a influência dos supervisores orientadores, tendo em vista os aspectos úteis e imediatos que Ihe garantam o sucesso acadêmico e profissional". 
Neste sentido, sou levada a questionar: por que a escola quase não acompanha o processo de formação inicial dos futuros profissionais que nela atuarão? Por que não ocorre a co-responsabilidade entre os Sistemas de Ensino previstos nas normativas legais? Entendo que assim, poderia ocorrer um trabalho mais sólido e consistente, possibilitando amenizar as lacunas na formação inicial do futuro professor.

\section{Considerações Finais}

Neste estudo busquei descrever aspectos que considero importantes sobre a configuração do Estágio Curricular a partir das alterações nas atuais normativas legais e, sobretudo, acerca do processo de organização e desenvolvimento de Estágio Curricular no Curso de Artes Visuais Licenciatura Plena em Desenho e Plástica da UFSM.

Constatei que, o Curso apresenta carga horária pouco superior a prevista pela legislação vigente para as atividades de Estágio Curricular, estando nesse ponto em acordo com a Resolução CNE/CP 2/2002.

A análise do Curso investigado mostrou que a maioria dos alunos estagiários elegeu as disciplinas de "Conhecimento de conteúdo específico" como as que mais contribuíram para a realização de Estágio Curricular, bem como proporcionaram uma base para sua formação inicial.

Dentre as formas de orientação utilizadas pelo professor orientador para preparar os alunos estagiários a desenvolverem seus Estágios Curriculares, pode-se afirmar que, há um bom empenho por parte desse docente em orientá-los em qualquer momento que haja necessidade de auxílio para melhorias na qualidade das aulas, bem como para resolver as dificuldades encontradas em sala de aula.

No que tange a aceitação e a recepção dos alunos estagiários, pode-se afirmar que, a maioria dos alunos estagiários foram bem recebidos por alguma pessoa que faz parte da equipe diretiva ou pelo professor regente da escola. E, essa boa receptividade se deve ao fato das escolas já possuírem um conhecimento sobre o trabalho que os estagiários referentes ao mesmo curso, bem como do mesmo professor orientador e da mesma Instituição de Ensino Superior (IES) costumam realizar nas escolas.

Nas informações levantadas, comprovei que o Estágio Curricular é considerado de extrema importância para a formação inicial dos futuros professores, além de proporcionar a inserção do aluno estagiário na realidade escolar. Parece, também, ter um papel decisivo no momento de verificar ou reafirmar a opção profissional. 
De modo geral, percebi que não há uma participação constante dos professores regente de turma junto aos alunos estagiários durante a realização do Estágio Curricular. Dessa maneira, pude afirmar que, a responsabilidade pela formação inicial do futuro professor está mais centrada na Instituição de Ensino Superior (IES). Tendo em vista que as Escolas de Educação Básica (EEB) parecem ainda não conceber o Estágio Curricular como uma forma de trabalho coletivo entre as agências formadoras, conforme previsto na Resolução CNE/CP 1/2002 em seu artigo 13, parágrafo 3, quando faz referencia à "colaboração entre os sistemas de ensino".

Logo, considero de extrema importância esse trabalho conjunto entre as EEB e as IES, frente às novas exigências legais, visando proporcionar uma formação de "melhor qualidade" aos estagiários, futuros profissionais do ensino. Porém, sabemos que a quantidade do número de horas destinadas ao Estágio Curricular não irá fazer nenhum diferencial na "qualidade" do profissional que se estará formando, se não houver comprometimento e responsabilidade pelas agências formadoras envolvidas neste processo formativo.

Neste sentido, esse estudo me trouxe várias indagações e dúvidas, tendo em vista que o "Estágio é um centro de questionamentos". Mas diante dessas inquietações pretendo ampliar meus estudos sobre essa etapa da Formação Inicial de Professores, visando encontrar caminhos que conduzam a superação das dificuldades enfrentadas para dimensões mais produtivas.

\section{Referências}

AGOSTINI, Sandra. A Organização e o Desenvolvimento de Estágios Curriculares em Cursos de Licenciatura da UFSM: Envolvimentos de Estagiários e Orientadores. Santa Maria/BRA: Programa de Pós-Graduação em Educação. Centro de Educação, Universidade Federal de Santa Maria, 2008. (Dissertação de Mestrado). Disponível em: <http://www.dominiopublico.gov.br/pesquisa/DetalheObraForm.do?

select_action $=\&$ co_obra $=110837>$

BARDIN, Laurence. Análise de Conteúdo. Lisboa: Edições 70, 1977.

BRASIL, Ministério da Educação. Lei de Diretrizes e Bases da Educação Nacional no 9.394/96 - Estabelece as Diretrizes e Bases da Educação Nacional. Brasília: MEC, 1996. Disponível em: <htt://www.planalto.gov.Br>. Acesso em: 17 abr. 2007.

BRASIL, Ministério da Educação. Conselho Nacional de Educação. Resolução CNE/CP 01, de 18 de fevereiro de 2002 - Institui Diretrizes Curriculares Nacionais para 
a Formação de Professores da Educação Básica, em nível superior, cursos de Licenciatura, de graduação plena. Diário Oficial da União, Brasília, 09 Abr. 2002, Seção 1, p.31, 2002.2 Disponível em: <htt://portal.mec.gov.Br/cne/arquivos/pdf/rcp01_02.pdf > Acesso em: 22 de mar. 2007.

BRASIL. Ministério da Educação. Conselho Nacional de Educação. Resolução CNE/CP 02, de 19 de fevereiro de 2002 - Institui a duração e a carga horária dos cursos de Licenciatura, de graduação plena, de formação de professores da Educação Básica em nível superior. Diário Oficial da União, Brasília, 04 Mar. 2002, Seção 1, p.9, 2002. Disponível em: <http://portal.mec.gov.br/cne/arquivos/pdf/CP022002.pdf.>. Acesso em: 22 fev. 2007.

GOLDENBERG, Mirian. A arte de pesquisar: como fazer pesquisa qualitativa em ciências sociais. 7. ed. Rio de Janeiro: Record, 2003.

LIMA, Maria Socorro Lucena et al. A hora da prática: reflexões sobre o estágio supervisionado e ação docente. 4. ed. Ver. E ampl. Fortaleza: Edições Demócrito Rocha, 2004.

MATOS, Kelma S. L; VIEIRA, Sofia L. Pesquisa Educacional: o prazer de conhecer. 2. ed. Fortaleza: Edições Demócrito Rocha, 2002.

MARCONI, Marina de Andrade; LAKATOS, Eva Maria. Fundamentos de metodologia científica. 5. ed. São Paulo: Atlas, 2003.

OLIVEIRA, Marilda O. de. A formação do professor e o ensino das Artes Visuais: o estágio Curricular como campo de conhecimento. In: OLIVEIRA, Marilda. O. de; HERNÁNDEZ, F. (Orgs.) A Formação do Professor e o Ensino das Artes Visuais. Santa Maria: Editora UFSM, p. 57-72, 2005.

PACHECO, José Augusto; FLORES, Maria Assunção. Formação e Avaliação de Professores. Porto: Porto Editora, 1999.

PÁDUA, Elisabete Matallo Marchesini de. Metodologia da pesquisa: abordagem teóricoprática. Campinas: Papirus, 1996.

PONTUSCHKA, Nídia N. A Formação Inicial do Professor de Geografia. In: PICONEZ, Stela C. B. (coord.). A Prática de ensino e o estágio supervisionado. SP: Papirus, 1991. 